\title{
Guidance of primordial germ cell migration
}

\section{Erez Raz}

Primordial germ cells (PGCs), the progenitors of the gametes, migrate from the position where they are specified towards the region where the gonad develops. To reach their target, the PGCs obtain directional cues from cells positioned along their migration path. One such cue, the chemokine SDF-1, has recently been found to be critical for proper PGC migration in zebrafish and in mice. In Drosophila, too, a molecule that is structurally related to chemokine receptors and is important for PGC migration has been identified. The ability to visualize chemokine-guided migration at a high resolution in vivo in these model organisms provides a unique opportunity to study this process, which is relevant for many events in normal development and disease.

\section{Addresses}

Germ Cell Development, Max-Planck-Institute for Biophysical Chemistry, Am Fassberg 11, 37070 Goettingen, Germany e-mail: eraz@gwdg.de

\section{Current Opinion in Cell Biology 2004, 16:169-173}

This review comes from a themed issue on

Cell regulation

Edited by Craig Montell and Peter Devreotes

0955-0674/\$ - see front matter

(c) 2004 Elsevier Ltd. All rights reserved.

\section{DOI 10.1016/j.ceb.2004.01.004}

\begin{tabular}{ll}
\multicolumn{2}{l}{ Abbreviations } \\
7-TM & seven transmembrane \\
HMGCoAr & 3-hydroxy-3-methylglutaryl coenzyme A reductase \\
PGC & primordial germ cell \\
SDF & stromal cell-derived factor \\
SGP & somatic gonadal precursor
\end{tabular}

\section{Introduction}

Organ development and function rely on cooperation among different cell types. In many cases, cells that form an organ originate some distance away from the place where the organ develops. Understanding the mechanisms that enable migrating cells to reach their targets is therefore a central theme in the study of organogenesis and of clinical conditions resulting from aberrant cell migration.

The gonad, the organ where the gametes are generated, is composed of two major cell populations, somatic and germ cells. The somatic cells of the gonad are crucial for supporting proper development of germ cells, the lineage that gives rise to sperm and eggs. Interestingly, in most organisms the germ cells are specified in positions that are distinct from the location where the gonad develops $[1,2]$.
Therefore, the germ cells (termed primordial germ cells or PGCs at this stage) have to migrate through the developing embryo and become incorporated in the developing gonad [1,2].

Analysis of PGC migration in different organisms supports the idea that the cells are guided towards their target by cues provided by somatic cells along their migration route [1]. Recently, molecules involved in providing the PGCs with directional information were identified. These findings, discussed in the context of previous studies, are the focus of this review.

\section{Guidance of PGC migration in Drosophila}

Drosophila PGCs (or pole cells) are formed earlier than the cells that constitute the somatic portion of the gonad and at a different location [1,3]. From the posterior part of the embryo, where they are specified, the PGCs move with the invaginating posterior midgut primordium towards the interior of the embryo. The PGCs leave the midgut by traversing its epithelium and assume a dorsal position so that they face the mesoderm. The PGCs then migrate toward the somatic gonadal precursor (SGP) cells with which they make contact and eventually coalesce to form a gonad. The initial translocation of the PGCs with the invaginating posterior midgut primordium is driven by the movement of the somatic cells, with the PGCs being passively carried along with the endodermal cells. In the next stage, however, the PGCs actively migrate through the gut. Yet this process too depends on the somatic cells that form intercellular spaces within the single-layered epithelium and thus allow the PGCs to transmigrate [4-6].

Following on from this work in wild-type embryos, extensive mutational analysis and the use of other genetic tools showed that PGC migration can be divided into distinct steps. In addition, several molecules required for the directed migration of PGCs were identified [7-12,13 ${ }^{\bullet}$. For example, the active migration through the gut epithelium was found to depend on the function of trapped in endoderm-1 (Figure 1a). This gene is expressed in PGCs and encodes a 7-transmembrane (7-TM) domain orphan receptor related to chemokine receptors $\left[13^{\bullet}\right]$. Considering that a role for this family of receptors in PGC migration has been demonstrated in zebrafish and mice (see below), signaling through 7-TM receptors could represent an evolutionarily conserved mechanism for guiding PGC migration. In addition, transepithelial migration requires the function of the small GTPase Rho1, presumably to allow specific alterations in actin cytoskeleton architecture to take place $\left[13^{\bullet}\right]$. After transversing the gut 
Figure 1

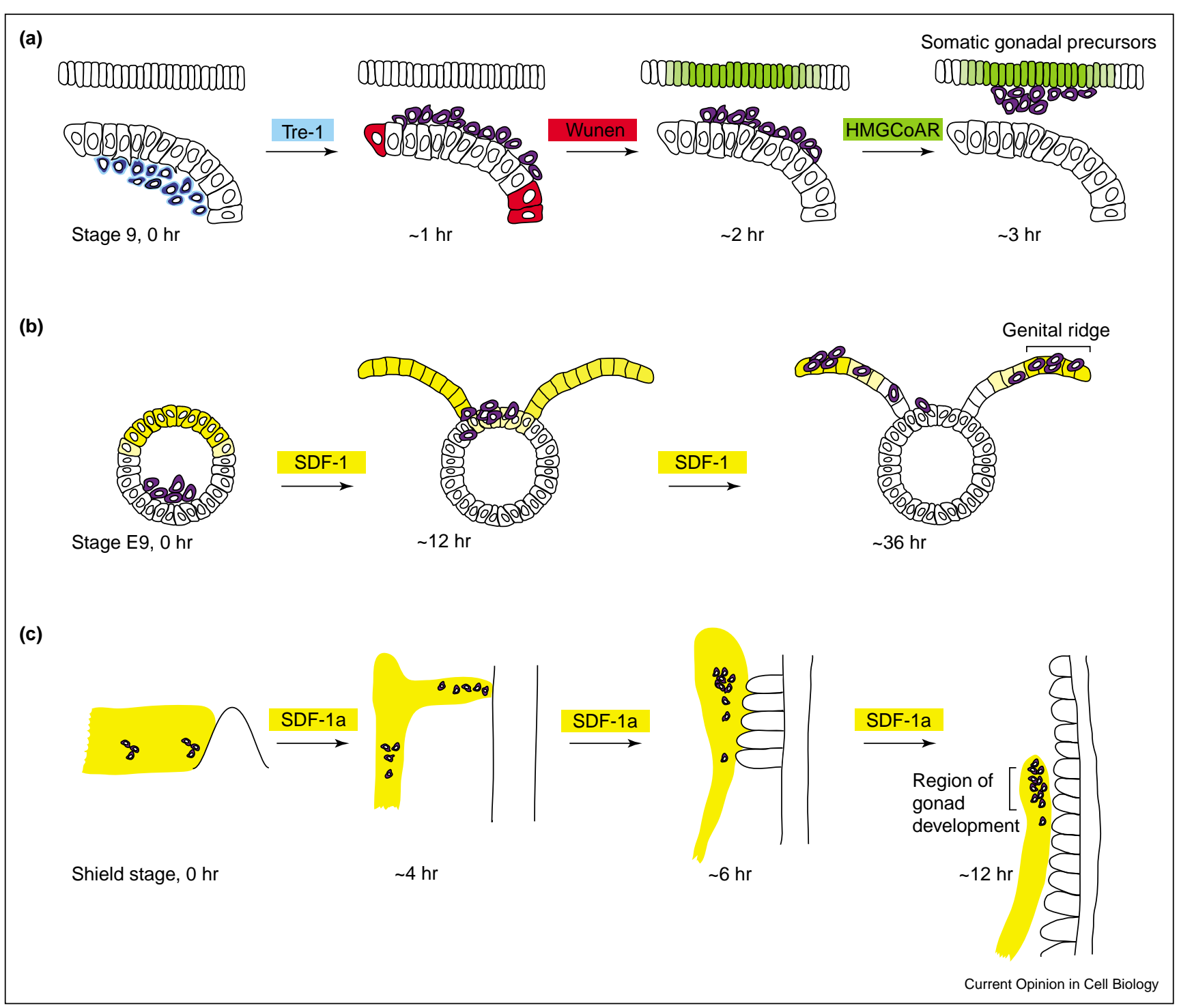

A simplified schematic representation of the spatial distribution of molecules relevant for guidance of PGC migration in Drosophila, mouse and zebrafish embryos. (a) Expression of trapped in endoderm-1 (Tre-1, blue) in the PGCs of Drosophila is required for transepithelial migration out of the posterior midgut. Once out of the posterior midgut, the PGCs are directed towards the mesoderm by the repulsive activity of Wunen and Wunen-2, which are expressed in certain areas of the posterior midgut (red). The PGCs are then attracted to the somatic gonadal precursor cells that express hmgcr (green). (b) At the 9th day of mouse embryonic development the PGCs are found at the ventral part of the hindgut. From there they migrate dorsally towards regions expressing SDF-1 (yellow) that directs them to the genital ridges. (c) Zebrafish PGCs are formed within a broad domain of SDF-1a expression (yellow). Alterations in the shape of this domain by control over the spatial activity of the sdf-1a promoter and simultaneous migration of the PGCs to domains that express the gene at high levels results in cell accumulation in the region where the gonad develops. For simplicity only the left half of the embryo is illustrated.

epithelium, two apparently independent and spatially distinct activities guide the PGCs towards the SGPs (Figure 1a). Wunen and Wunen-2, homologues of mammalian lipid phosphate phosphatases, generate a repulsive environment directing the PGCs toward the mesoderm [7,11]. Subsequently, 3-hydroxy-3-methylglutaryl coenzyme A reductase (HMGCoAr, columbus) is responsible for generating an attractive environment in the target region [9]. Although the precise mode of action of HMGCoAr has not yet been reported, this enzyme is expressed in the mesodermal target and controls a ratelimiting step in the mevalonate pathway; HMGCoAr could therefore be important for the production of a compound used to modify the actual attractant (e.g. a lipid used in protein modification).

In conclusion, these studies highlight the significance of interactions between the somatic cells and the migrating 
cells, interactions that ensure that the developing gonad becomes populated by PGCs. The somatic cells can play either a permissive role (e.g. by altering midgut epithelium properties and thus allowing PGC migration) or an instructive role (e.g. by producing repulsive and attractive signals).

\section{Guidance of PGC migration in mouse}

Despite the anatomical differences between the embryos and the different mode of PGC specification [14-16], in principle the migration path of mouse PGCs is similar to that described above for Drosophila. After the endoderm invaginates to form the hindgut, PGCs are found along the ventral side of the forming organ. Leaving this site, the PGCs migrate actively through the dorsal aspect of the gut and then perform directed migration towards the genital ridge $[17,18]$.

As in Drosophila, a role for somatic tissues in supporting the directed migration was demonstrated in mouse. For example, PGCs lacking $\beta 1$-integrin do not colonize the gonad efficiently [19]. This finding underscores the importance of interactions between the PGC and the extracellular matrix. Importantly, Godin et al. [20] have demonstrated in vitro that the genital ridge tissue can attract PGCs, although the molecule responsible for this activity is not known. Additional molecules have been implicated in guiding mouse PGCs, such as the $c$-kit receptor tyrosine kinase, which is expressed in the PGCs, and its ligand Steel, which is expressed by somatic cells along the migratory route. It was suggested that receptorligand interaction between these molecules is required to support migration and survival of the PGCs [21-23], but a direct demonstration of the role of Steel as a guidance cue is still lacking. Therefore, it is possible that $c$-kit signaling plays only a permissive role by supporting proliferation and survival of migrating mouse PGCs.

The most promising candidate for a signaling molecule that guides mouse PGCs is the chemokine stromal cellderived factor 1 (SDF-1). In the context of PGC guidance, this molecule was originally identified in zebrafish $\left[24^{\bullet \bullet}\right]$. The receptor for SDF-1, the 7-TM domain protein CXCR4, is expressed in mouse germ cells, whereas expression of its ligand is high in the genital ridge and the gonad, the targets of the migrating cells $\left[25^{\bullet}, 26^{\bullet \bullet}\right]$ (Figure 1b). The requirement for chemokine signaling for colonization of the gonad by PGCs was demonstrated by studying the process in mice deficient for the activity of the receptor $\left[26^{\bullet \bullet}\right]$ or the ligand $\left[25^{\circ}\right]$. In both cases, specification and arrival at the position in the gut from which the PGCs initiate their dorsal migration was not affected, but the mutant mice showed a substantial decrease in the number of PGCs that were able to reach the genital ridge. The impaired colonization of the gonad in the mutant mice appears to reflect a dual role for CXCR4 signaling in PGC development: in addition to the apparent defects in guidance, the total PGC number was reduced, revealing a function for CXCR4 in controlling cell proliferation and/or survival $\left[26^{\bullet \bullet}\right]$. The best evidence for SDF-1 playing a direct role in guiding mouse PGCs comes from live cultures of the hindgut region, where SDF-1 can influence the migration of GFP-labeled PGC $\left[26^{\bullet \bullet}\right]$. Specifically, application of exogenous SDF-1 inhibited the migration of the PGCs toward the genital ridges, presumably by interfering with the generation of positional information by the endogenous ligand. Furthermore, SDF-1-coated beads producing high local concentrations of the protein can attract migrating germ cells and alter their migration trajectories.

In summary, as in Drosophila, mouse PGC migration depends on permissive interactions with somatic cells and on instructive cues that guide them towards their target. Our ability to follow the migration process using the slice culture setup, together with the availability of mice deficient for the receptor and/or the ligand, should facilitate thorough investigation of chemokine-directed cell migration.

\section{Guidance of PGC migration in zebrafish}

Among the organisms discussed in this review, the process of reaching the gonad appears to be most challenging in zebrafish PGCs. In contrast to the single defined migration starting points in mouse and Drosophila, zebrafish PGCs are specified in four positions that are randomly oriented with respect to the axis of the embryo [27,28]. Notably, despite this seemingly complex situation, virtually all cells reach their target within the first day of development. The robustness of PGC migration in zebrafish was convincingly demonstrated in experiments in which PGCs transplanted to a region destined to give rise to head structures were nevertheless able to reach the gonad [29]. In an attempt to understand the mechanisms that allow the cells to reach their target, the PGC migration path was determined in wild type and mutant embryos and the behavior of PGCs in live embryos was followed (Figure 2). This analysis led to the definition of six migration steps, some of which involve active migration and some passive migration in which PGCs are carried along by the movement of somatic tissues $\left[28,30^{\circ}\right]$.

The main conclusions drawn from these studies were as follows: first, that PGCs depend on guidance cues from somatic cells; second, that the directional cues are attractive; and third, that on their way to the region of the gonad, the cells pass through domains within the embryo that constitute intermediate targets $\left[28,30^{\bullet}, 31\right]$. The results of these studies reveal how the PGCs arrive at a common target irrespective of their starting point. Briefly, a broad domain of attractive environment is formed in the early embryo that includes the positions in which the PGCs are specified. Dynamic changes in the shape of this 


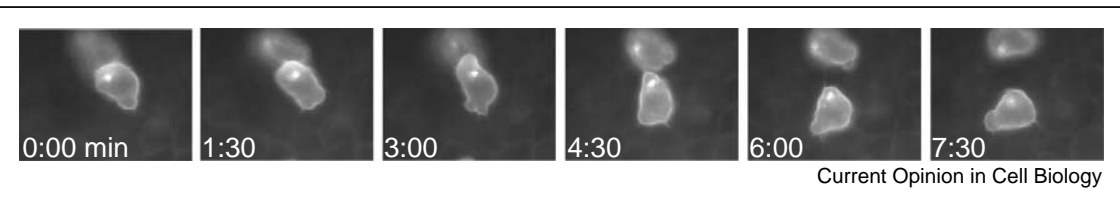

Active migration of zebrafish PGCs in vivo. Snapshots of PGCs expressing GFP on their membrane showing the formation of cellular protrusions in the leading edge and active migration relative to the weakly labelled neighbouring somatic cells. Photographs taken at intervals of 1 minute and 30 seconds spanning 7 minutes and 30 seconds of development.

domain and the resulting migration of the PGCs culminates in the accumulation of PGCs in two clusters in the position where the gonad develops.

The molecule responsible for attracting zebrafish PGCs towards their intermediate and final targets is the chemokine SDF-1a, a secreted molecule that is expressed in domains previously defined as attractive to PGCs (Figure 1c) $\left[24^{\bullet \bullet}, 31\right]$. In mutant embryos in which the expression pattern of SDF-1a is changed as a result of abnormal somatic development, PGC migration is altered and corresponds to the new expression profile of the gene $\left[24^{\bullet \bullet}\right]$. Similarly, expression of SDF-1a in ectopic locations is sufficient to attract the PGCs to these positions $\left[24^{\bullet \bullet}\right.$ ]. Finally, in embryos in which the activity of SDF$1 \mathrm{a}\left[24^{\bullet \bullet}\right]$ or its receptor CXCR4b $\left[24^{\bullet \bullet}, 32\right]$ is reduced, the cells arrive at ectopic positions, thus proving that SDF-1a serves as the endogenous directional cue for zebrafish PGCs. It is noteworthy that the cells in which SDF-1a signaling is inhibited are motile, but in contrast to wildtype PGCs they show non-directional migration and exhibit less-polar cell morphology [24••].

\section{Conclusions}

Over the past few years, the field of PGC migration has advanced significantly, primarily as a result of the identification of molecules that serve as directional cues for the cells. These findings make the study of PGC migration, a classical topic in developmental biology, directly relevant to work on the development of other organs [33,34], stem cell homing [35,36], leukocyte trafficking [37,38] and neuronal cell migration $[33,39]$, in which the same molecules are utilized. Moreover, the numerous recent demonstrations of the role of CXCR4 in tumor formation and the spreading of malignant cells $\left[40,41,42^{\bullet \bullet}\right]$ make the research of PGC migration pertinent to this subject too. The accessibility of the zebrafish and Drosophila embryos and the techniques that permit visualization of live PGC migration in the mouse provide excellent experimental systems in which these processes can be explored.

\section{Acknowledgements}

The author wishes to acknowledge the support of the DFG and the Volkswagen-Stiftung for some of the work reviewed here and Michal Reichman for critical reading of the manuscript.

\section{References and recommended reading}

Papers of particular interest, published within the annual period of review, have been highlighted as:

- of special interest

$\bullet$ of outstanding interest

1. Starz-Gaiano M, Lehmann R: Moving towards the next generation. Mech Dev 2001, 105:5-18.

2. Niewkoop PD, Sutasurya LA: Primordial germ cells in the chordates: embryogenesis and phylogenesis. Cambridge University Press 1979.

3. Campos-Ortega JA, Hartenstein V: The Gonads. In The Embryonic Development of Drosophila melanogaster. Springer; 1997:279-285

4. Jaglarz M, Howard K: Primordial germ cell migration in Drosophila melanogaster is controlled by somatic tissue. Development 1994, 120:83-89.

5. Jaglarz MK, Howard KR: The active migration of Drosophila primordial germ cells. Development 1995, 121:3495-3503.

6. Callaini G, Riparbelli MG, Dallai R: Pole cell migration through the gut wall of the Drosophila embryo: analysis of cell interactions. Dev Biol 1995, 170:365-375.

7. Zhang N, Zhang J, Purcell KJ, Cheng Y, Howard K: The Drosophila protein Wunen repels migrating germ cells. Nature 1997 , 385:64-67.

8. Moore LA, Broihier HT, Van Doren M, Lunsford LB, Lehmann R: Identification of genes controlling germ cell migration and embryonic gonad formation in Drosophila. Development 1998, 125:667-678.

9. Van Doren M, Broihier HT, Moore LA, Lehmann R: HMG-CoA reductase guides migrating primordial germ cells. Nature 1998, 396:466-469.

10. Coffman CR, Strohm RC, Oakley FD, Yamada Y, Przychodzin D, Boswell RE: Identification of $X$-linked genes required for migration and programmed cell death of Drosophila melanogaster germ cells. Genetics 2002, 162:273-284.

11. Starz-Gaiano M, Cho NK, Forbes A, Lehmann R: Spatially restricted activity of a Drosophila lipid phosphatase guides migrating germ cells. Development 2001, 128:983-991.

12. Stein JA, Broihier HT, Moore LA, Lehmann R: Slow as molasses is required for polarized membrane growth and germ cell migration in Drosophila. Development 2002, 129:3925-3934.

13. Kunwar PS, Starz-Gaiano M, Bainton RJ, Heberlein U,

- Lehmann R: Tre1, a G-protein-coupled receptor, directs transepithelial migration of Drosophila germ cells. PLOS Biol 2003, 1:E80.

In this study, a 7-TM receptor whose function is important for trans epithelial migration of Drosophila PGCs is described. Its structural similarity to chemokine receptors, together with the findings that this class of receptors is required for PGC migration in other organisms, suggests that the molecular mechanisms controlling PGC migration are conserved.

14. Lawson KA, Hage WJ: Clonal analysis of the origin of primordial germ cells in the mouse. Ciba Found Symp 1994, 182:68-84. 
15. Lawson KA, Dunn NR, Roelen BA, Zeinstra LM, Davis AM, Wright $\mathrm{CV}$, Korving JP, Hogan BL: Bmp4 is required for the generation of primordial germ cells in the mouse embryo. Genes Dev 1999, 13:424-436.

16. McLaren A: Primordial germ cells in the mouse. Dev Biol 2003, 262:1-15.

17. Anderson R, Copeland TK, Scholer H, Heasman J, Wylie C: The onset of germ cell migration in the mouse embryo. Mech Dev 2000, 91:61-68.

18. Molyneaux KA, Stallock J, Schaible K, Wylie C: Time-lapse analysis of living mouse germ cell migration. Dev Biol 2001, 240:488-498.

19. Anderson R, Fassler R, Georges-Labouesse E, Hynes R, Bader B, Kreidberg J, Schaible K, Heasman J, Wylie C: Mouse primordial germ cells lacking beta1 integrins enter the germline but fail to migrate normally to the gonads. Development 1999 , 126:1655-1664.

20. Godin I, Wylie C, Heasman J: Genital ridges exert long-range effects on mouse primordial germ cell numbers and direction of migration in culture. Development 1990, 108:357-363.

21. Matsui $Y$, Zsebo K, Hogan B: Embryonic expression of a haematopoietic growth factor encoded by the SI locus and the ligand for c-kit. Nature 1990, 347:667-669.

22. Bernex F, De Sepulveda P, Kress C, Elbaz C, Delouis C, Panthier JJ: Spatial and temporal patterns of c-kit-expressing cells in WlacZ/+ and WlacZ/WlacZ mouse embryos. Development 1996, 122:3023-3033.

23. De Miguel MP, Cheng L, Holland EC, Federspiel MJ, Donovan PJ: Dissection of the c-Kit signaling pathway in mouse primordial germ cells by retroviral-mediated gene transfer. Proc Natl Acad Sci U S A 2002, 99:10458-10463.

24. Doitsidou M, Reichman-Fried M, Stebler J, Koprunner M, Dorries J,

- Meyer D, Esguerra CV, Leung T, Raz E: Guidance of primordial germ cell migration by the chemokine SDF-1. Cell 2002 111:647-659.

The first demonstration of the involvement of chemokine signaling in PGC migration. The roles of SDF-1a and its receptor CXCR4b in guiding the PGCs are demonstrated and the effect of knocking down the activity of these molecules on cell behavior and morphology is described.

25. Ara T, Nakamura $Y$, Egawa T, Sugiyama T, Abe K, Kishimoto T,

- Matsui Y, Nagasawa T: Impaired colonization of the gonads by primordial germ cells in mice lacking a chemokine, stromal cell-derived factor-1 (SDF-1). Proc Natl Acad Sci U S A 2003, 100:5319-5323.

The first demonstration of the role of SDF-1 signaling in PGC migration in mouse. Analysis of SDF-1-deficient mice showed that SDF-1 is importan for colonization of the gonad by PGCs.

26. Molyneaux K, Zinszner H, Kunwar P, Schaible K, Stebler J,

- Sunshine M, O'Brien W, Raz E, Littman D, Wylie C et al.: The chemokine SDF1/CXCL12 and its receptor CXCR4 regulate mouse germ cell migration and survival. Development 2003 130:4279-4286.

A detailed analysis of the role of CXCR4 and its ligand SDF-1 in PGC migration in the mouse. In addition to showing that CXCR4 is required for colonization of the gonad, analysis of PGC migration in slice cultures supports the notion that SDF-1 provides the cells with directional cues. An additional role for SDF-1 in promoting PGCs survival is demonstrated.

27. Yoon C, Kawakami K, Hopkins N: Zebrafish vasa homologue RNA is localized to the cleavage planes of 2- and 4-cell-stage embryos and is expressed in the primordial germ cells. Development 1997, 124:3157-3165.
28. Weidinger G, Wolke U, Koprunner M, Klinger M, Raz E: Identification of tissues and patterning events required for distinct steps in early migration of zebrafish primordial germ cells. Development 1999, 126:5295-5307.

29. Ciruna B, Weidinger G, Knaut $H$, Thisse B, Thisse C, Raz E, Schier AF: Production of maternal-zygotic mutant zebrafish by germ-line replacement. Proc Natl Acad Sci U S A 2002, 99:14919-14924.

30. Weidinger G, Wolke U, Koprunner M, Thisse C, Thisse B, Raz E:

- Regulation of zebrafish primordial germ cell migration by attraction towards an intermediate target. Development 2002, 129:25-36.

This work shows that zebrafish PGCs migrate actively and use intermediate targets on the way to their final target.

31. Raz E: Primordial germ-cell development: the zebrafish perspective. Nat Rev Genet 2003, 4:690-700.

32. Knaut H, Werz C, Geisler R, Nusslein-Volhard C: A zebrafish homologue of the chemokine receptor Cxcr4 is a germ-cell guidance receptor. Nature 2003, 421:279-282.

33. Zou YR, Kottmann AH, Kuroda M, Taniuchi I, Littman DR: Function of the chemokine receptor CXCR4 in haematopoiesis and in cerebellar development. Nature 1998, 393:595-599.

34. Tachibana K, Hirota S, lizasa H, Yoshida H, Kawabata K, Kataoka Y, Kitamura Y, Matsushima K, Yoshida N, Nishikawa S et al:: The chemokine receptor CXCR4 is essential for vascularization of the gastrointestinal tract. Nature 1998, 393:591-594.

35. Peled A, Petit I, Kollet O, Magid M, Ponomaryov T, Byk T, Nagler A Ben-Hur H, Many A, Shultz L et al.: Dependence of human stem cell engraftment and repopulation of NOD/SCID mice on CXCR4. Science 1999, 283:845-848.

36. Petit I, Szyper-Kravitz M, Nagler A, Lahav M, Peled A, Habler L, Ponomaryov T, Taichman RS, Arenzana-Seisdedos F, Fujii N et al.: G-CSF induces stem cell mobilization by decreasing bone marrow SDF-1 and up-regulating CXCR4. Nat Immunol 2002 , 3:687-694.

37. Bleul C, Fuhlbrigge R, Casasnovas J, Aiuti A, Springer T: A highly efficacious lymphocyte chemoattractant, stromal cell-derived factor 1 (SDF-1). J Exp Med 1996, 184:1101-1109.

38. Aiuti A, Webb I, Bleul C, Springer T, Gutierrez-Ramos J: The chemokine SDF-1 is a chemoattractant for human CD34 ${ }^{+}$ hematopoietic progenitor cells and provides a new mechanism to explain the mobilization of $\mathrm{CD} 34^{+}$progenitors to peripheral blood. J Exp Med 1997, 185:111-120.

39. Xiang Y, Li Y, Zhang Z, Cui K, Wang S, Yuan XB, Wu CP, Poo MM, Duan $S:$ Nerve growth cone guidance mediated by $\mathrm{G}$ protein coupled receptors. Nat Neurosci 2002, 5:843-848.

40. Muller A, Homey B, Soto H, Ge N, Catron D, Buchanan ME, McClanahan T, Murphy E, Yuan W, Wagner SN et al:: Involvement of chemokine receptors in breast cancer metastasis. Nature 2001, 410:50-56.

41. Zeelenberg IS, Ruuls-Van Stalle L, Roos E: The chemokine receptor CXCR4 is required for outgrowth of colon carcinoma micrometastases. Cancer Res 2003, 63:3833-3839.

42. Staller P, Sulitkova J, Lisztwan J, Moch H, Oakeley EJ, Krek W:

-. Chemokine receptor CXCR4 downregulated by von HippelLindau tumour suppressor pVHL. Nature 2003, 425:307-311.

A convincing demonstration of the critical role of CXCR4 signaling in tumor cell metastasis. The molecular mechanisms governing CXCR4 expression are defined and a strong correlation between CXCR4 expression and patient survival is shown. 